\title{
Relative Importance, Specific Investment and Ownership in Interorganizational Systems
}

\author{
Kunsoo Han \\ Desautels Faculty of Management \\ McGill University \\ Kunsoo.han@mcgill.ca \\ Robert J. Kauffman \\ W. P. Carey School of Business \\ Arizona State University \\ rkauffman@asu.edu \\ Barrie R. Nault \\ Haskayne School of Business \\ University of Calgary \\ nault@ucalgary.ca
}

October 5, 2007

We thank the Special Issue co-editors (Indranil Bardhan, Alok Gupta, and Paul Tallon) and two anonymous reviewers for Information Technology and Management. We gratefully acknowledge comments on earlier versions of this paper from participants of the 2004 Workshop on Information Systems and Economics (WISE), the Leverhulme Project Conference on Digital Transformations at the London Business School, the MIS Colloquium Series at the University of Calgary, the CIS Research Seminar at the University of Michigan, and the Information and Decision Sciences Workshop at the Carlson School of Management of the University of Minnesota for their input. We also thank the Natural Science and Engineering Research and the Social Science and Humanities Research Councils of Canada; the Centre for Research on Information Technology in the Desautels Faculty of Management at McGill University; the W. P. Carey Chair and the Center for Advancing Business through Information Technology at the W. P. Carey School of Business, Arizona State University; the MIS Research Center of the Carlson School of Management, University of Minnesota; and the David B. Robson Professorship Endowment and the Informatics Research Center in the Haskayne School of Business at the University of Calgary for generous support. Earlier versions of this paper were titled "Who Should Own 'IT'? Ownership and Incomplete Contracts in Interorganizational Systems" and "Ownership in Procurement Systems." 


\title{
Relative Importance, Specific Investment and Ownership in Interorganizational Systems
}

\begin{abstract}
Implementation and maintenance of interorganizational systems (IOS) require investments by all the participating firms. Compared with intraorganizational systems, however, there are additional uncertainties and risks. This is because the benefits of IOS investment depend not only on a firm's own decisions, but also on those of its business partners. Without appropriate levels of investment by all the firms participating in an IOS, they cannot reap the full benefits. Drawing upon the literature in institutional economics, we examine IOS ownership as a means to induce value-maximizing noncontractible investments. We model the impact of two factors derived from the theory of incomplete contracts and transaction cost economics: relative importance of investments and specificity of investments. We apply the model to a vendor-managed inventory system (VMI) in a supply chain setting. We show that when the specificity of investments is high, this is a more critical determinant of optimal ownership structure than the relative importance of investments. As technologies used in IOS become increasingly redeployable and reusable, and less specific, the relative importance of investments becomes a dominant factor. We also show that the bargaining mechanism - or the agreed upon approach to splitting the incremental payoffs - that is used affects the relationship between these factors in determining the optimal ownership structure of an IOS.
\end{abstract}

Keywords: Economic theory, incomplete contracts, interorganizational information systems, investment specificity, information systems, IT investments, ownership, property rights, relative importance, supply chain management. 


\section{Introduction}

Interorganizational systems (IOS) are information systems (IS) that facilitate the exchange of products, services and information between firms (Bakos, 1991; Johnston and Vitale, 1988). With the rapid increase in business-to-business (B2B) transactions, IOS are becoming ever more valuable. Examples include EDI systems, vendor-managed inventory (VMI), collaborative planning, forecasting, and replenishment (CPFR) in a supply chain, B2B electronic marketplaces, and systems for information sharing in financial services.

Implementation of IOS requires various noncontractible investments by participating firms including systems integration and data synchronization.1 Compared with intraorganizational systems, there is additional uncertainty and risk as the benefits depend not only on a firm's own decisions but also on those of its business partners (Gebauer and Buxmann, 2000). Moreover, because IOS investments benefit the partners of the investing firm, it may not be possible for organizations to reap the full benefit. Consequently, investments may be held up, resulting in underinvestment. This was reported in a survey by Booz Allen Hamilton and Giga Information Group (2001), which found that most companies were unsatisfied with the B2B e-procurement exchanges they participated in due to a slowdown in investments by the market-making intermediaries. Another more recent example of underinvestment in IOS has been reported related to healthcare. A large-scale empirical study of three large urban healthcare markets in the United States found that policy changes and financial incentives to clinicians is pivotal for them to make sufficient investments in healthcare IT relative to achieving improved future performance (Poon et al., 2006). Without appropriate levels of investments by all the participating firms in these and other settings, an IOS-deploying

\footnotetext{
${ }^{1}$ The implementation of IOS requires two types of investments related to IT assets. The first kind is system asset acquisition investment. This includes hardware, software packages, and network and communications technologies. System assets acquisition investments typically can be specified in a contract between the partners involved in developing the system. Such investments are typically part of the contractual responsibilities of ownership. The second type is systems implementation effort investment. Such investment typically occurs alongside the system asset acquisitions, and includes systems and process redesign, systems integration, data conversion, data synchronization, and maintenance to ensure continued interoperability. These investments cannot be easily specified in a contract and hence they are noncontractible. Without these complementary noncontractible investments, the acquisition of hardware, software and network technologies is not sufficient to produce business value in IOS. We focus on noncontractible investments throughout this article.
} 
firm cannot set the stage for full potential value and the participants cannot realize the full benefits from their IOS.

One solution to this problem of underinvestment is to have a central coordinator who can dictate how much investment each participant needs to make (Brynjolfsson, 1994). Such a coordinator seldom exists in reality; it would need information about whether the investments have been carried out. Although participants' investments may be observable to the coordinator, they may not be verifiable by a third party, such as an arbitrator or a court (Hart, 1995). Similarly, vertical integration can be a solution, but it is not practical in many situations due to the costs involved (Williamson, 1985) $!^{2}$ Writing a contract on the investments and value sharing among the participants is another solution. Every contract, however, is incomplete in the sense that all of the possible contingencies cannot be written into a contract (Williamson, 1985).

Drawing upon transaction cost economics (TCE), the theory of incomplete contracts, and bargaining theory, we investigate IOS ownership as a partial solution to this investment coordination problem. We argue that creating the "right" ownership structure can help coordinate IOS participants' investments by giving them proper incentives to invest. This, in turn, can help the participants increase the value from their IOS investments. In this study, we define an IOS as a set of IT assets that support business relationships. IOS ownership structure identifies which participant owns the IOS assets. We investigate how IOS participants should decide on the ownership structure of their IOS to maximize the value they can capture.

Ownership of an asset is relevant to consider because of the incompleteness of contracts. Asset ownership implies the right to decide what to do with the asset-including the right to exclude other participants from using that asset - in circumstances not covered by a contract (Grossman and Hart, 1986; Hart and Moore, 1990). Thus, the asset owner has stronger bargaining power relative to non-owners after the investments are made, and can capture a larger share of the value created from the asset. This share of the value affects the

\footnotetext{
${ }^{2}$ In addition, there can be relational solutions, such as trust about continuity of the relationship and coercion based on market power (Hart and Saunders, 1997). We do not consider them in this article though.
} 
participants' investment incentives $3^{3}$

We define relative importance of participants' investments as the relative contribution of participants' IOS-related investments to the value of IOS, and examine the mechanism by which relative importance of participants' investments determines which IOS ownership structure is optimal. (See Appendix A for the definitions of the key concepts.)

This definition emphasizes which IOS participant's noncontractible investments have a greater impact on the value of the IOS. For example, in the context of VMI between a buyer and a supplier, if the quality of the data from the buyer is most critical in the operation of the VMI system, then the buyer's investments for improving the quality of the inventory and sales data (e.g., integration of the VMI system with the POS and inventory management systems) will have a greater impact on the value of the VMI system compared to the supplier's investments. On the contrary, if accurately forecasting demand and liking this information to production planning is the most critical part of the VMI system, then the supplier's investments in improving the quality of the forecasting algorithm and integrating the VMI system with its production planning system will have a bigger impact on the value of the VMI system.

Another key transaction cost factor that impacts the optimal ownership structures is asset specificity, defined as the degree to which the value of an asset is reduced when it is redeployed to alternative uses (Williamson, 1996). In this article, we define the specificity of investments as a loss in the value of a participant's IOS-related investments when the IOS asset is used outside the current IOS relationship. In the context of VMI, specificity of investment can be interpreted in terms of how many alternative trading partners the buyer and the supplier have with whom they can reuse the VMI asset. If the buyer (e.g., Wal-Mart) has a large number of suppliers with whom it can reuse the VMI system asset (e.g., by forcing them to comply with the information that is exchanged through its use), its specificity of investment is low. In contrast, the supplier's investment is highly specific if the supplier does not have many trading partners or if every buyer has different system

\footnotetext{
${ }^{3}$ Brynjolfsson (1994) introduced the concept of "information asset" and Walden (2005) and Walden and Wetherbe (2005) examined the optimal ownership structure of an information asset (intellectual property) in the context of IT outsourcing.
} 
specifications and requirements with which the supplier needs to comply.

Despite their significance as key determinants of optimal ownership structures, prior research has not investigated the relative importance of investments and specificity of investments together. We present an incomplete contracting model that incorporates these two determinants in a single model. Our model builds on Hart and Moore (1990) and Bakos and Nault (1997) by explicitly considering the specificity of investments.

The rest of the article is organized as follows. $\S 2$ reviews related literature that informs this study. $§ 3$ introduces VMI, our illustrative example of IOS. $§ 4$ describes the modeling preliminaries including notation, definitions, and assumptions. $\S 5$ analyzes two cases that differ in modeling assumptions, and solves the model for equilibrium investments under alternative ownership structures. $\S 6$ presents the main results in the form of four propositions that show the relationship among the relative importance of investments, the specificity of investments, and the optimal ownership structure. $\S 7$ discusses the results and concludes with a consideration of the limitations of our approach.

\section{Related Literature}

\subsection{Incomplete Contracts and Relative Importance of Investments}

The theory suggests that there are four major determinants of optimal asset ownership: the complementarities between assets, the essentiality of an asset to a participant, the indispensability of a participant to an asset, and the relative importance of participants' investments (Hart and Moore, 1990; Brynjolfsson, 1994; Bakos and Nault, 1997). We refer to the latter in terms of the relative contribution of participants' investments to the total value created by the coalition, where a coalition is defined as a set of participants who cooperate to create joint value. Prior work in economics and IS focused on complementarities, essentiality, and indispensability (e.g., Hart and Moore, 1990; Brynjolfsson, 1994; Bakos and Nault, 1997). We argue that advances in IT have made these three determinants less important as compared to relative importance of participants' investment in determining optimal ownership structures. We consider each of these in turn. 
Complementarities. There are strict complementarities between two or more IT assets if they cannot create value unless they are used together. Development of open standards and the emergence of technology adapters (Dai and Kauffman, 2002) are two factors that have led to a decrease in complementarities between IT assets. This has made it easier for IOS investment participants to connect their own IT assets with otherwise incompatible technologies. For example, St. Paul, Minnesota-based SPS Commerce provides an "anyto-any transformation engine" that ensures interoperability between any supplier and any buyer using different formats for document exchange (e.g., EDI, XML and flat files) (SPS Commerce, 2007).

Essentiality. An IT asset is essential to a participant in an IOS if the participant cannot create any value from investment without access to the asset. With fiercer competition among hardware vendors and software solution providers, today there are a number of competing IT products that are available to IOS participants. This availability of alternative substitutable IT assets has made any single IT asset less essential to the participants. For example, various types of demand forecasting software solutions for VMI are available in the marketplace (e.g.,Vendor Managed Inventory.com, 2007). These include Demand Solutions Inc.'s (www.demandsol.com) "Rough Cut" software to match production capacity to market demand and Jada Management Systems' (www.jadaman.com) "NetVMI" buyer-to-supplier demand sharing software.

Indispensability. A participant is indispensable to an asset if the asset cannot create any value without the participant. In early implementations of IOS such as EDI, the system provider had specific know-how and technical expertise for software development and system management, making its sole ownership optimal. In the presence of the growing competition among vendors with comparable technical capabilities, and sophistication on the part of IOS participants, however, the expertise necessary to implement and operate an effective IT infrastructure has become more broadly available (Bakos and Nault, 1997). As a result, today, a single participant is rarely the owner of an entire IOS due to its decreasing indispensability.

Because these three determinants appear to be decreasing in their impact on ownership, 
we focus on the role of relative importance of participants' investments in determining optimal ownership structures, and assume that no participant is indispensable to the assets. We do this because in the presence of an indispensable participant, it is always optimal for the participant to own the assets regardless of the relative importance (Bakos and Nault, 1997).

Then, what are the sources of relative importance of investments? We argue that a critical source of relative importance is the difference in the participating firms' specific knowledge and know-how that can contribute to creating value for the coalition. Such knowledge may be difficult and costly to transfer because it is hard to codify (i.e., tacit) and "sticky" (Jensen and Meckling, 1992; Brynjolfsson, 1994; von Hippel, 1994). For example, knowledge about complex systems integration is difficult to codify and transfer because such knowledge is specific to a particular context. When one participant possesses more valuable specific knowledge that can help create grater value for the coalition, it is optimal to give that

participant ownership of the coalition's assets (Brynjolfsson, 1994). The more knowledgeable participant has greater incentives to invest when it owns the assets.

Another possible source of relative importance is the size of the participating firm. Larger firms can more easily achieve economies of scale by using the same or similar system assets in their relationships with a number of business partners. Furthermore, the effectiveness of management can affect participants' relative importance. In addition to these internal sources, there can be external factors that affect which participants' investments are more important too. For example, regulations can restrict some participants' investment activities, and so it may be more profitable to give asset ownership to the participant with less restricted IT investment opportunities.

\subsection{Transaction Cost Economics and Specificity of Investments}

Transactions cost economics is concerned with examining the differences in costs of planning, adapting, and monitoring tasks under different ownership structures (i.e., market vs. hierarchy) (Williamson, 1985). The main argument is that transactions take place under the ownership structure that minimizes the transaction costs. Williamson (1985) identifies three variables that affect the transaction costs, and hence the optimal ownership structure: 
frequency, uncertainty, and asset specificity. Among these, asset specificity has been the most critical variable. In the presence of transaction costs, asset specificity increases governance costs for all forms of governance and when asset specificity is high, then integration has advantages relative to non-integration. Numerous TCE-based empirical studies found that vertical integration prevails if asset specificity is high (e.g., Anderson, 1985; John and Weitz, 1988).

To incorporate asset specificity into our model along with relative importance of investments, we employ the concept of specificity of investments. As defined earlier, specificity of a participant's investments is a relationship between the participant and IOS assets within the interfirm relationship supported by the IOS. When an IOS participant (e.g., a buyer) makes investments in implementation and maintenance of IOS within a relationship with a business partner (e.g., a supplier), the IOS assets are specialized and customized to the relationship. This specialization of assets increases the specificity of its investments. ${ }^{4}$ The specificity of investments can be different between two participants in an IOS relationship because each participant may have a different set of alternative opportunities in which it can reuse the IOS assets. The specificity of investments in IOS also affects the payoffs that the IOS owner(s) can receive when redeploying or reusing the IOS outside the current relationship.

\subsection{Cooperative Game Theory and Bargaining Solutions}

A popular solution concept for distributing surplus in a two-person bargaining game is the Nash bargaining solution (Nash, 1953). This is relevant to bilateral IOS, and more specifically to EDI or VMI between a supplier and a buyer. For a two-person bargaining game, the Nash bargaining solution entails a 50:50 split of the incremental value between the two participants involved in a bilateral relationship. This is the additional value the two participants can create jointly beyond the sum of the value each participant can create on its own. For example, Clemons and Kleindorfer (1992) applied this approach in a model of

\footnotetext{
${ }^{4}$ Because implementation of IOS always involves some degree of customization and integration with internal corporate systems such as enterprise resource planning systems, specificity of investments always arise even under complete standardization of technologies. We thank one of the anonymous reviewers for this point.
} 
firms' investments in IOS and value sharing among the participants..$^{5}$

Another concept related to bargaining is that of disagreement payoffs, which participants receive when they fail to reach an agreement. There are two types of disagreement payoffs: threat points and outside options. Threat points refer to the payoffs that the participants engaged in bargaining receive when the bargaining process continues with no agreement reached. In contrast, outside options refer to the payoffs that the participants receive when the bargaining has been permanently terminated and each participant uses outside opportunities without the other participant's collaboration (Chiu, 1998). The key distinction between these two concepts is that taking the outside option means giving up the original opportunity for cooperation with the bargaining partner, while adopting a threat point does not rule out the possibility of cooperation in the future. Binmore et al. (1986) suggest that the inclusion of an outside option affects the equilibrium outcome of the bargaining games if at least one of the participants prefers its outside option to one of the agreement outcomes ${ }^{6}$

In the context of IOS, the threat points are the different amounts of value that accrue to the IOS participants even when they do not reach an agreement on all the aspects of the IOS operation. For example, without reaching an agreement to share the critical information (e.g., real-time sales and inventory data from the buyer), the supplier and the buyer can still benefit from a VMI system by performing standard electronic transactions through EDI (e.g.,

\footnotetext{
${ }^{5}$ For more general multi-person bargaining games, this solution is not appropriate because it ignores the possibility of cooperation among subsets or coalitions of participants (Myerson, 1991). In the context of IOS, multi-person bargaining situations arise in such multilateral IOS as B2B electronic marketplaces, supporting transactions between multiple buyers and suppliers, and in shared electronic banking networks. The unique solution for n-person bargaining games is the Shapley value. The basic concept is to give each participant an amount equal to that participant's expected marginal contribution, the additional value that the participant can contribute to each potential coalition by joining the coalition, multiplied by the probability of each such coalition occurring during the formation of the coalition of all the participants.

${ }^{6}$ The incomplete contracting models used by Grossman, Hart and Moore assume that the disagreement payoffs are threat points rather than outside options. Several studies showed that Hart and Moore's results may not hold if we interpret disagreement payoffs as outside options (Chiu, 1998; de Meza and Lockwood, 1998). When the disagreements are threat points in bilateral bargaining as in Grossman, Hart, and Moore, and the Nash bargaining solution, each participant receives its disagreement payoff plus half of the additional value created from cooperation. In other words, the disagreement payoffs always matter. Because participants' disagreement payoffs always increase with asset ownership, a participant's investment incentives are always greater when it is the owner than when it is not. When disagreement payoffs are interpreted as outside options as in Chiu (1998) and de Meza and Lockwood (1998), the participant whose outside option binds receives a payoff equal to its outside option and the other participant receives the rest of the surplus.
} 
purchase orders, invoices, advanced shipment notices, etc.). The potential value of VMI (e.g., from an accurate forecast of demands based on the buyer's real-time sales and inventory data) cannot be fully realized though, until they agree to share the critical information.

In contrast, the value of a participant's outside option is the value the participant can capture when the participant terminates the business relationship with its current IOS partner, which frees its IOS assets for use in other business relationships. For example, suppose the buyer owns the VMI asset in a procurement relationship with a supplier. Then, the buyer's outside option value related to the VMI asset is the value the asset can create for the buyer when it is redeployed and reused in the relationships with other suppliers. In this regard, the outside option is closely related to the specificity of investment; the more specific a participant's investment to a relationship, the lower is the value of its outside option. Therefore, we expect that outside options will become more valuable as technologies become more open and standardized, and less specific to a certain relationship.

\section{Illustration: Vendor-Managed Inventory (VMI)}

We use VMI in supply chain management to show how relative importance and specificity of investments impact optimal ownership structures in IOS. VMI is one of the most widelyadopted supply chain initiatives for improving efficiency between a supplier (usually a manufacturer) and a buyer (usually a retailer or distributor). Pioneered by Wal-Mart and Procter \& Gamble in 1980s, VMI has been adopted as an integral part of such strategic initiatives as the "Efficient Consumer Response" in the grocery industry and the "Quick Response" in the apparel industry (Seidmann and Sundararajan, 1997; Waller et al., 1999). In current automated applications of VMI, the supplier is responsible for managing the buyer's inventory, and makes inventory replenishment decisions for the buyer based on demand and inventory information sent by the buyer.

As shown in Figure 1, VMI system assets consist of network technologies and EDI for

communication and data sharing, forecasting software for market demand forecasting and placing orders based on sales and inventory data, and a point-of-sale (POS) system and 


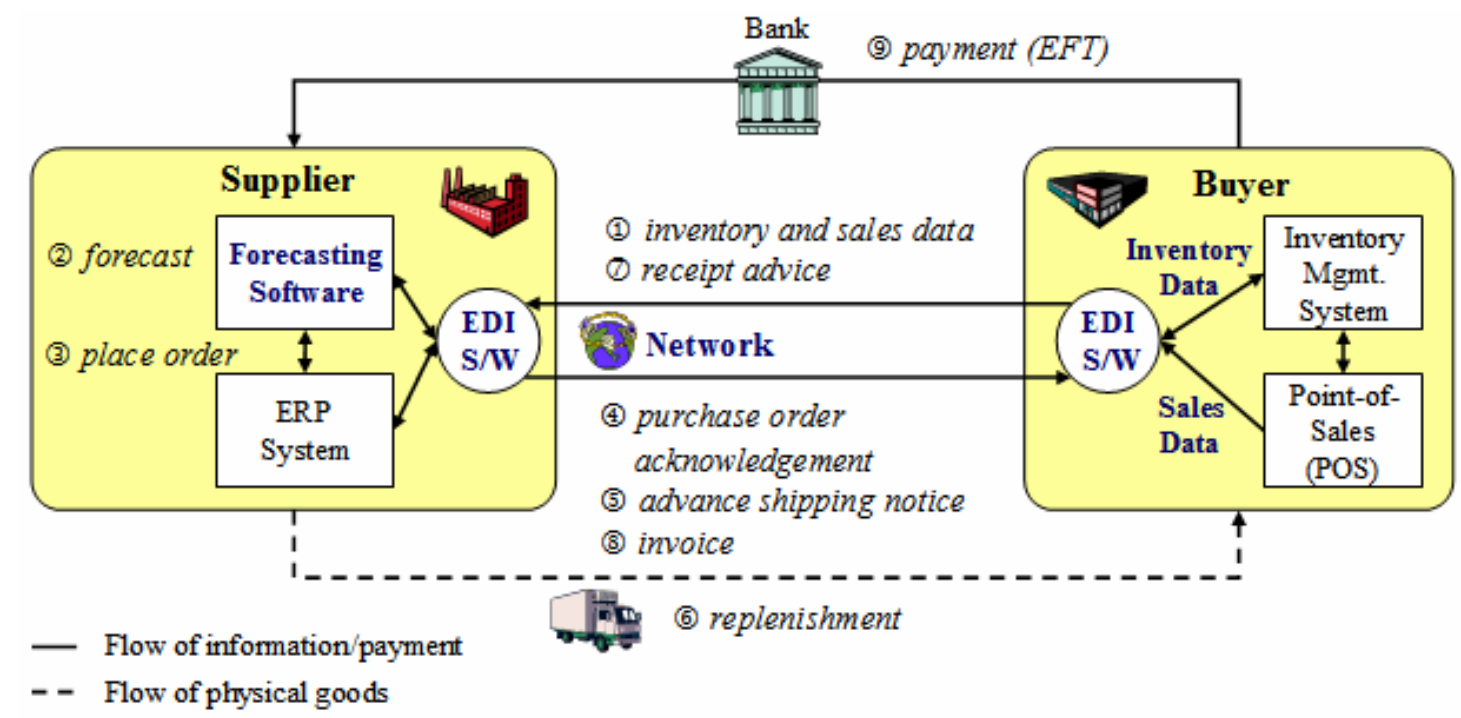

Note: The numbers indicate the order in which the transactions take place.

Figure 1: Typical Components and Inventory Replenishment Process in VMI

retail inventory system for gathering sales and inventory data. Even though a VMI system consists of a number of assets as described, we treat the VMI system as a single asset. This is because it can be shown that having all the assets under common ownership maximizes the total value created from the system. In addition to the investments in the acquisition of the system assets that are contractible, both participants must also make noncontractible investments in systems implementation efforts, including integrating these new systems with their existing internal systems, achieving technological interoperability, and data standardization and synchronization for key data, such as new items and inventory counts, etc. VMI implementation also requires other noncontractible investments to create the necessary organizational structure, such as planning, aligning business processes and information systems, etc. (Waller et al., 1999).

The most valuable benefit of VMI for both the supplier and the buyer is increased sales from improved service levels or reduced stockouts. The buyer's other benefits include a decrease in inventory levels, and planning and ordering costs. The supplier's costs decrease because the increased visibility of the buyer's sales and inventory data allows it to better 
forecast demand, plan production, prioritize production and logistics, and reduce its inventory levels - all resulting in improved resource utilization. These investments and benefits are listed in Table 1.

\begin{tabular}{|c|c|c|}
\hline & SUPPLIER & BUYER \\
\hline Investments & $\begin{array}{l}\text { - EDI implementation } \\
\text { - Standardization of data for EDI } \\
\text { - VMI software implementation } \\
\text { - Systems integration (ERP or order } \\
\text { processing system, VMI, EDI, etc.) } \\
\text { - Process reengineering } \\
\text { - Data standardization and } \\
\text { synchronization } \\
\text { - Network service for data interchange }\end{array}$ & $\begin{array}{l}\text { - EDI implementation } \\
\text { - Standardization of data for EDI } \\
\text { - POS implementation } \\
\text { - Systems integration (EDI, POS, and } \\
\text { inventory management, etc.) } \\
\text { - Process reengineering } \\
\text { - Data standardization and synchronization } \\
\text { - Network service for data interchange }\end{array}$ \\
\hline Benefits & $\begin{array}{l}\text { - Increased sales } \\
\text { - Improved demand forecasting and } \\
\text { reduced demand uncertainty } \\
\text { - Smaller buffers of production capacity } \\
\text { and inventory } \\
\text { - Reduced transportation costs } \\
\text { - More efficient route planning }\end{array}$ & $\begin{array}{l}\text { - Increased sales (due to improved service } \\
\text { levels and reduced stockouts) } \\
\text { - Reduced inventory levels } \\
\text { - Eliminating planning/ordering costs } \\
\text { - Reduced time for order fulfillment }\end{array}$ \\
\hline
\end{tabular}

Table 1: Investments and Benefits Associated with VMI Implementation

\section{Modeling Assumptions and Setup}

We use an incomplete contracting model for two-firm bargaining. Drawing upon Bakos and Brynjolfsson (1993) and the example in Bakos and Nault (1997), we employ specific functional forms to analyze how relative importance and specificity of IOS investments are related in determining the participants' investment incentives and optimal ownership structures. Definitions of the modeling notation are summarized in Appendix B.

In our model, there are two firms, the buyer $(b)$ and the supplier $(s)$, who make investments $x_{b}, x_{s} \in[0, \bar{x}]$, where $\bar{x} \geq 0$. These are noncontractible investments in systems implementation effort, such as data synchronization and process redesign. When the buyer and the supplier remain in the IOS, they can create joint value, $V\left(x_{b}, x_{s}\right) \geq 0$, for the relationship from their VMI system in terms of reduced inventory levels and increased sales. This joint value function is increasing at a decreasing rate, is twice continuously differentiable in 
$x_{b}$ and $x_{s}$, and satisfies:

$$
V(0,0)=0,\left.\frac{\partial V(\cdot)}{\partial x_{i}}\right|_{x_{i}=0}=\infty,\left.\frac{\partial V(\cdot)}{\partial x_{i}}\right|_{x_{i}=\bar{x}}=0, i \in\{s, b\} .
$$

The buyer and the supplier incur investment costs, $c\left(x_{i}\right) \geq 0, i \in\{s, b\}$. As is common in incomplete contracting models, $c\left(x_{i}\right)$ is assumed to be increasing at an increasing rate and twice continuously differentiable in $x_{i}$, and satisfies $c(0)=0, c^{\prime}(0)=0$, and $c^{\prime}(\bar{x})=\infty$. We use the quadratic form for $\operatorname{costs} c\left(x_{i}\right)=x_{i}^{2} / 2, i \in\{s, b\}$ for both cases that we will shortly lay out.

When the buyer and the supplier cannot reach an agreement in bargaining, they receive their disagreement payoffs, or stand-alone values, $r_{i}\left(x_{i} \mid a\right) \geq 0, i \in\{s, b\}, a \in\{0,1\}$. Here, $a$ represents whether the buyer owns the VMI asset $(a=1)$ or the supplier owns it $(a=0)$. We assume that when a participant does not own the VMI asset, it cannot create any value outside the relationship, that is, $r_{b}\left(x_{b} \mid a=0\right)=r_{s}\left(x_{s} \mid a=1\right)=0$. When participant $i$ is the owner of the VMI asset, $r_{i}\left(x_{i} \mid a\right)$ is assumed to be increasing at a decreasing rate and twice continuously differentiable in $x_{i}$, and it satisfies $r_{i}(0 \mid a)=0, r_{i}^{\prime}(0 \mid a)=\infty$, and $r_{i}^{\prime}(\bar{x} \mid a)=0$.

We use the following functional form for joint value:

$$
V\left(x_{b}, x_{s}\right)=\omega x_{b}+(1-\omega) x_{s}+\mu x_{b} x_{s}, 0 \leq \omega, \mu \leq 1,
$$

where the parameter $\omega$ represents the relative importance of the buyer's investment, and $\mu$ represents the size of the positive externalities between the two participants' IOS investments.7 Positive investment externalities mean that the buyer's and the supplier's noncontractible VMI investments are complementary, enriching each other's value. For each participant's stand-alone value, we use the form

$$
r_{b}\left(x_{b}\right)=a \omega\left(1-\theta_{b}\right) x_{b}, r_{s}\left(x_{s}\right)=(1-a)(1-\omega)\left(1-\theta_{s}\right) x_{s}, a \in\{0,1\}, 0 \leq \theta_{b}, \theta_{s}, \omega \leq 1 .
$$

\footnotetext{
${ }^{7}$ We do not consider negative externalities. They occur when one participant's investment hurts the other participant, reducing its investment incentives. In our VMI context, however, it is unlikely that the buyer's investment in VMI implementation has a negative impact on the supplier, or vice versa. Negative externalities normally exist among competing firms. Riggins et al. (1994) and Wang and Seidmann (1995) analyze situations with negative or competitive externalities among competing suppliers when they adopt EDI.
} 
For simplicity, we use $r_{i}\left(x_{i}\right)$ to represent participant $i$ 's stand-alone value, suppressing $a$. The parameters $\theta_{b}$ and $\theta_{s}$ represent the specificity of the buyer's and the supplier's investment. Specificity of investment is modeled as a loss in investment value: the value of participant $i$ 's IOS investment is reduced by $\theta_{i}$ when the IOS is used outside the relationship (e.g., due to customization or specialization of technologies).

Our model consists of two periods. (See Figure 2.) Before the first period, the ownership structure of the VMI asset is determined. Once this occurs, the buyer and the supplier write a contract. This contract can only be an incomplete one; it is not possible for the firms to write down contractual provisions that deal with every contingency. In Period 1, the buyer and the supplier choose the levels of noncontractible investments in VMI. In Period 2 , the value is shared between the buyer and the supplier according to the Nash bargaining solution, representing a 50:50 split of incremental value that the two together produce.

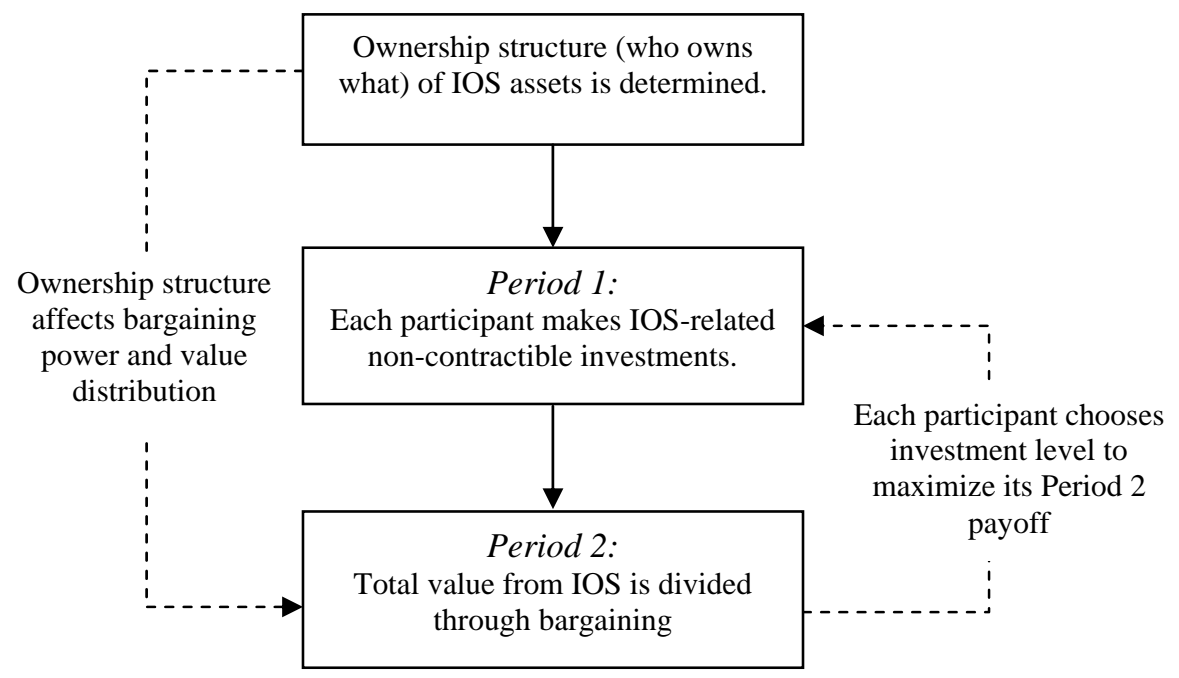

Note: The optimal ownership structure maximizes the total value that can be created in Period 2 by entailing the greatest expected marginal return for each participant.

Figure 2: Timing of the Model for Investments and Ownership Analysis

From Figure 2, we can see that the ownership structure affects the bargaining power of the participants and the distribution of value among them in Period 2. This value distribution, 
in turn, affects the levels of noncontractible investments each participant chooses in Period 1. These investments determine the total value created from the VMI system. In other words, the VMI asset ownership structure determines the ex post value from the asset by affecting the levels of ex ante investments. The optimal ownership structure of VMI maximizes the total value created from VMI by maximizing each participant's expected marginal return on investment and, in turn, their investment incentives.

\section{Analysis of Optimal Ownership Structures}

We consider two ownership structures for VMI assets: supplier ownership and buyer ownership. We do not analyze joint ownership because the payoffs to joint ownership are lower than these two alternatives. When the VMI asset is jointly owned, a participant cannot reuse the entire asset in alternative opportunities when the current relationship breaks down. This reduces participants' investment incentives, and the total value created. For different values of relative importance and specificity of investments under the two ownership structures, we compare the participants' investment incentives. In each case, an ownership structure is optimal if it entails a greater total surplus for the relationship.

To compare how different modeling assumptions affect the outcomes of the model, we analyze two cases. In the first case, we use the standard Nash bargaining solution. In the second case, we use a different bargaining mechanism for distributing the surplus: the outside option principle. This permits us to investigate how this change in the bargaining solution affects the equilibrium investments and optimal ownership structures. As a benchmark, we analyze the first-best scenario where an integrated firm owns the VMI asset and makes its own investment decisions. In each case, we first calculate the participants' equilibrium levels of investments for first-best, supplier ownership, and buyer ownership. Then, we determine which ownership structure is optimal by comparing the total surplus under various conditions. 


\subsection{Case 1: Nash Bargaining}

Applying the 50:50 split of the incremental value represented by the Nash bargaining solution, the two participants' payoffs are determined as follows:

$$
\begin{gathered}
\text { Buyer's Payoff: } \pi_{b}=r_{b}\left(x_{b}\right)+\frac{1}{2}\left\{V\left(x_{b}, x_{s}\right)-r_{b}\left(x_{b}\right)-r_{s}\left(x_{s}\right)\right\}-c\left(x_{b}\right) \\
\text { Supplier's Payoff: } \pi_{s}=r_{s}\left(x_{s}\right)+\frac{1}{2}\left\{V\left(x_{b}, x_{s}\right)-r_{b}\left(x_{b}\right)-r_{s}\left(x_{s}\right)\right\}-c\left(x_{s}\right)
\end{gathered}
$$

For either participant, the first term is the stand-alone value, the second term is half of the incremental value from cooperation (the difference between the joint value and the sum of stand-alone values), and the last term is the cost of investment.

When an integrated firm owns the VMI asset, it chooses investment levels to maximize its own total surplus net of the costs:

$$
T\left(x_{b}, x_{s}\right)=\omega x_{b}+(1-\omega) x_{s}+\mu x_{b} x_{s}-\frac{1}{2}\left(x_{b}^{2}+x_{s}^{2}\right) .
$$

The quasi-concavity and convexity of the value function and the cost function ensure that there is a unique solution that satisfies the first-order conditions. Solving for the investments yields

$$
x_{s}^{*}=\frac{1-\omega+\mu \omega}{1-\mu^{2}}, x_{b}^{*}=\frac{\omega+\mu-\mu \omega}{1-\mu^{2}},
$$

where we use the superscript $*$ to indicate first-best.

When the supplier is the sole owner of the VMI asset, each participant maximizes its own payoff by equating the marginal benefit and the marginal cost. Solving the first-order conditions for the investments yields a unique solution:

$$
x_{b}^{S O}=\frac{2(1-\omega)\left(2-\theta_{s}\right)+\mu \omega}{4-\mu^{2}}, x_{s}^{S O}=\frac{2 \omega+\mu(1-\omega)\left(2-\theta_{s}\right)}{4-\mu^{2}} .
$$

The buyer ownership of the VMI asset is the mirror image of the supplier ownership. Solving the first-order conditions, we obtain another unique solution:

$$
x_{s}^{B O}=\frac{2(1-\omega)+\mu \omega\left(2-\theta_{b}\right)}{4-\mu^{2}}, x_{b}^{B O}=\frac{2 \omega\left(2-\theta_{b}\right)+\mu(1-\omega)}{4-\mu^{2}} .
$$


As we explained earlier, Hart and Moore's model and our use of the Nash bargaining solution assume that the disagreement payoffs are threat points rather than outside options. The impact of this assumption is that asset ownership always increases the owner's investment incentives.

\subsection{Case 2: Outside Option Principle}

We next turn to an application of the outside option principle as the bargaining solution and examine how this approach affects the firms' equilibrium investments and optimal ownership structures.

Following Binmore et al. (1989), we take the disagreement point as the impasse point where neither participant gains value from the VMI. Using this disagreement point and applying the outside option principle means that if a participant's (e.g., the supplier's) outside option value exceeds one-half of the total surplus from the VMI relationship (i.e., if its outside option binds), the participant receives the value of its outside option while the other participant (e.g., the buyer) gets the remainder of the total surplus from the VMI. When neither outside option binds, then the total surplus is shared equally. From this, we can see that outside options play the role of a constraint on the optimal value of an ownership structure. If we let $\left(s_{b}, s_{s}\right)$ denote the surplus pair of the buyer and the supplier, then the outside option principle can be represented as:

$$
\left(s_{b}, s_{s}\right)= \begin{cases}\left(r_{b}, V-r_{b}\right) & \text { if } V / 2 \leq r_{b} \\ \left(V-r_{s}, r_{s}\right) & \text { if } V / 2 \leq r_{s} \\ (V / 2, V / 2) & \text { if } r_{s}, r_{b}<V / 2\end{cases}
$$

Based on this, we first calculate the supplier's and the buyer's payoffs under each ownership structure. To focus on the impact of the outside option, we assume that there are no externalities between participants' investments via $\mu=0$. When the buyer is the sole owner of VMI, $V\left(x_{b}, x_{s}\right)=\omega x_{b}+(1-\omega) x_{s}$ and $r_{b}\left(x_{b}\right)=\omega\left(1-\theta_{b}\right) x_{b}, r_{s}\left(x_{s}\right)=0$. Note that only the owner's (the buyer in this case) outside option binds because the non-owner's outside option value is zero in our model. Applying the outside option principle, we get the following 
surplus pair for the participants:

$$
\left(s_{b}, s_{s}\right)= \begin{cases}\left(\omega\left(1-\theta_{b}\right) x_{b},(1-\omega) x_{s}+\omega \theta_{b} x_{b}\right) & \text { if }(1-\omega) x_{s} \leq \omega\left(1-2 \theta_{b}\right) x_{b} \\ \left(\frac{\omega x_{b}+(1-\omega) x_{s}}{2}, \frac{\omega x_{b}+(1-\omega) x_{s}}{2}\right) & \text { if }(1-\omega) x_{s}>\omega\left(1-2 \theta_{b}\right) x_{b} .\end{cases}
$$

Under supplier ownership of VMI, the outside options are: $r_{b}=0, r_{s}=(1-\omega)\left(1-\theta_{s}\right) x_{s}$. The resulting surpluses are:

$$
\left(s_{b}, s_{s}\right)= \begin{cases}\left(\omega x_{b}+(1-\omega) \theta_{s} x_{s},(1-\omega)\left(1-\theta_{s}\right) x_{s}\right. & \text { if } \omega x_{b} \leq(1-\omega)\left(1-2 \theta_{s}\right) x_{s} \\ \left(\frac{\omega x_{b}+(1-\omega) x_{s}}{2}, \frac{\omega x_{b}+(1-\omega) x_{s}}{2}\right) & \text { if } \omega x_{b}>(1-\omega)\left(1-2 \theta_{s}\right) x_{s}\end{cases}
$$

From the above expressions we observe the following. First, the owner's outside option binds only when its investment is relatively non-specific (i.e., $\theta_{i}<0.5$ ). Second, the owner's outside option is more likely to bind when its investment is relatively more important (i.e., when $\omega>0.5$ under buyer ownership and when $\omega<0.5$ under supplier ownership) than that of the non-owner. In addition, the buyer's and the supplier's surpluses remain the same regardless of ownership structure when neither participant's outside option binds. We next calculate equilibrium investment levels.

When the integrated firm owns the VMI asset, it chooses investment levels that maximize the total surplus. Again, the quasi-concavity and convexity of the value functions and the cost functions ensure the existence of a unique solution. Solving for the investments yields:

$$
x_{b}^{*}=\omega, x_{s}^{*}=(1-\omega) \text {. }
$$

When either the buyer or the supplier is the sole owner, the two participants' payoffs depend on whether the owner's outside option binds, so we have to analyze both situations. Again, only the owner's outside option binds because in our model the non-owner's outside option value is zero. We denote participant $i$ 's equilibrium investment level when $j$ 's outside option is binding by $x_{i}^{j *}$, where $i \in\{s, b\}, j \in\{s, b, n\}$. Here, $j=n$ means that neither outside option binds.

When the supplier's outside option binds, the payoffs are:

$$
\pi_{b}=\omega x_{b}+(1-\omega) \theta_{s} x_{s}-\frac{x_{b}^{2}}{2}, \pi_{s}=(1-\omega)\left(1-\theta_{s}\right) x_{s}-\frac{x_{s}^{2}}{2} .
$$


Solving the corresponding first-order conditions yields:

$$
x_{b}^{s *}=\omega, x_{s}^{s *}=(1-\omega)\left(1-\theta_{s}\right) .
$$

When the supplier's outside option does not bind (and hence neither outside option binds), the payoffs become:

$$
\pi_{b}=\frac{\omega x_{b}+(1-\omega) x_{s}-x_{b}^{2}}{2}, \pi_{s}=\frac{\omega x_{b}+(1-\omega) x_{s}-x_{s}^{2}}{2} .
$$

The resulting equilibrium investments are:

$$
x_{b}^{n *}=\frac{\omega}{2}, x_{s}^{n *}=\frac{1-\omega}{2} .
$$

Under buyer ownership, only the buyer's outside option can bind. When the buyer's outside option binds, the participants receive the following payoffs:

$$
\pi_{b}=\omega\left(1-\theta_{b}\right) x_{b}-\frac{x_{b}^{2}}{2}, \pi_{s}=(1-\omega) x_{s}+\omega \theta_{b} x_{b}-\frac{x_{s}^{2}}{2} .
$$

The equilibrium investments are:

$$
x_{b}^{b *}=\omega\left(1-\theta_{b}\right), x_{s}^{b *}=(1-\omega) .
$$

When the buyer's outside option does not bind (and hence neither outside option binds), the equilibrium investments are the same as $\left(x_{b}^{n *}, x_{s}^{n *}\right)$ under the supplier's ownership.

The equilibrium investment levels in each case are summarized in Table 2. We observe that both participants underinvest relative to the first-best levels under Nash bargaining (Case 1). If the outside option principle is applied (Case 2), when the owner's outside option is binding, only the non-owner of the VMI asset makes a first-best level investment. Otherwise, both the buyer and the supplier underinvest. Moreover, in Case 2, when the owner's outside option binds, its investment level is lower than when it does not own the VMI asset. This is consistent with de Meza and Lockwood (1998) and Chiu (1998), whose results showed that when the outside option principle is used as the bargaining solution, asset ownership may reduce the investment incentives. 


\begin{tabular}{|c|c|c|}
\hline \multirow[b]{2}{*}{ First-best } & Case 1: Nash Bar & Case 3: Outside Options \\
\hline & $\begin{aligned} x_{b}^{*} & =\frac{\omega+\mu-\mu \omega}{1-\mu^{2}} \\
x_{s}^{*} & =\frac{1-\omega+\mu \omega}{1-\mu^{2}}\end{aligned}$ & $\begin{array}{l}x_{b}^{*}=\omega \\
x_{s}^{*}=(1-\omega)\end{array}$ \\
\hline \multirow{2}{*}{$\begin{array}{l}\text { Supplier } \\
\text { ownership } \\
\text { (SO) }\end{array}$} & \multirow{2}{*}{$\begin{array}{l}x_{b}^{S O}=\frac{2 \omega+\mu(1-\omega)(2-\theta s)}{4-\mu^{2}} \\
x_{s}^{S O}=\frac{2(1-\omega)(2-\theta s)+\mu \omega}{4-\mu^{2}}\end{array}$} & $\begin{array}{l}\text { If the supplier's outside option binds, } \\
x_{b}^{s^{*}}=\omega, X_{s}^{s^{*}}=(1-\omega)\left(1-\theta_{s}\right)\end{array}$ \\
\hline & & $\begin{array}{l}\text { If the supplier's outside option does not bind, } \\
x_{b}^{n^{*}}=\frac{\omega}{2}, x_{s}^{n^{*}}=\frac{(1-\omega)}{2}\end{array}$ \\
\hline \multirow{2}{*}{$\begin{array}{l}\text { Buyer } \\
\text { ownership } \\
\text { (BO) }\end{array}$} & \multirow{2}{*}{$\begin{array}{l}x_{b}^{B O}=\frac{2 \omega\left(2-\theta_{b}\right)+\mu(1-\omega)}{4-\mu^{2}} \\
x_{s}^{B O}=\frac{2(1-\omega)+\mu \omega\left(2-\theta_{b}\right)}{4-\mu^{2}}\end{array}$} & $\begin{array}{l}\text { If the buyer's outside option binds, } \\
x_{b}^{b^{*}}=\omega\left(1-\theta_{b}\right), x_{s}^{b^{*}}=(1-\omega)\end{array}$ \\
\hline & & $\begin{array}{l}\text { If the buyer's outside option does not bind, } \\
x_{b}^{n^{*}}=\frac{\omega}{2}, x_{s}^{n^{*}}=\frac{(1-\omega)}{2}\end{array}$ \\
\hline
\end{tabular}

Table 2: Equilibrium Investment Levels

\section{Results and Implications}

We provide four propositions based on our analysis of the two cases. They show how relative importance, specificity, and externalities in investments in VMI implementation affect the equilibrium investments by the participants and the optimal ownership structure for the VMI asset. Our results also indicate that details of how incremental value is shared by the participating firms - in particular, different interpretations of disagreement payoffs - affect the equilibrium outcomes.

The first proposition is concerned with the impact of the factors of interest on equilibrium investment levels: relative importance of investment, specificity of investment, and positive investment externalities.

Proposition 1 (Equilibrium Investments) Regardless of the bargaining mechanism (Nash bargaining or the outside option principle), a participant's investment in VMI implementation effort is greater when: (1) the relative contribution of its investment to the total value (the relative importance of its investment) is greater $\left(\partial x_{s} / \partial \omega \leq 0, \partial x_{b} / \partial \omega \geq 0\right)$; (2) its in- 
vestment is less specific ( $\left.\partial x_{i} / \partial \theta_{i} \leq 0, i \in\{s, b\}\right)$; and (3) the positive investment externalities are greater $\left(\partial x_{i} / \partial \mu \geq 0, i \in\{s, b\}\right)$.

Proof: Checking the signs of the first derivatives of the equilibrium investments in Table 2 yields the results.

Our result that a participant's investment is greater when its investment is relatively more important is consistent with prior studies (Bakos and Nault, 1997; Hart and Moore, 1990). The second result is novel and intuitive. For example, when the supplier's investment is specific to the current VMI relationship with the buyer, the value of the supplier's investment is small outside the current relationship. This may be because the supplier has to modify its own system to comply with the buyer's requirements (e.g., a proprietary EDI standard). Therefore, the supplier's incentive for VMI-related investment is reduced.

The positive relationship between the positive investment externalities and the investment levels is also expected. Positive investment externalities imply that the participants' investments are complementary. For example, the value from the supplier's investment to improve its forecasting algorithm for VMI may increase if the buyer makes an investment to increase the accuracy of its inventory and sales data. Expecting the increase in the value, the supplier makes a greater investment.

Our next proposition states one of our key results: the relationship between specificity of investment and relative importance of investment is the key determinant of optimal ownership structures of the VMI asset.

\section{Proposition 2 (Specificity, Relative Importance of Investments, and Optimal}

Ownership) Let $\omega_{k}$ and $\theta_{k}, k \in\{i, j\}$, denote the relative importance and specificity of investment of the corresponding participant. Under the Nash bargaining solution, it is optimal for participant $i$ to own the VMI asset if and only if $\omega_{i}^{2}\left(1-\theta_{i}\right)\left\{4\left(1+\theta_{i}\right)+\mu^{2}\left(5-3 \theta_{i}\right)\right\}>$ $\omega_{j}^{2}\left(1-\theta_{j}\right)\left\{4\left(1+\theta_{j}\right)+\mu^{2}\left(5-3 \theta_{j}\right)\right\}$.

Proof: See Appendix C. 
From the proposition, we see that when the relative importance of investment (specificity of investment) is the same for both participants, the participant whose investment is less specific (more important) should be the owner 8 When one participant's investment is more important though, it may be optimal for the other participant to be the owner if the investment of the former is more specific. For example, in the left panel of Figure 3, the supplier's investment is more important because $\omega<0.5$. Still, the total surplus under supplier ownership may be smaller, making $T^{S O}-T^{B O}$ negative, when the supplier's investment is very specific (i.e., $\theta_{s} \approx 1$ ).
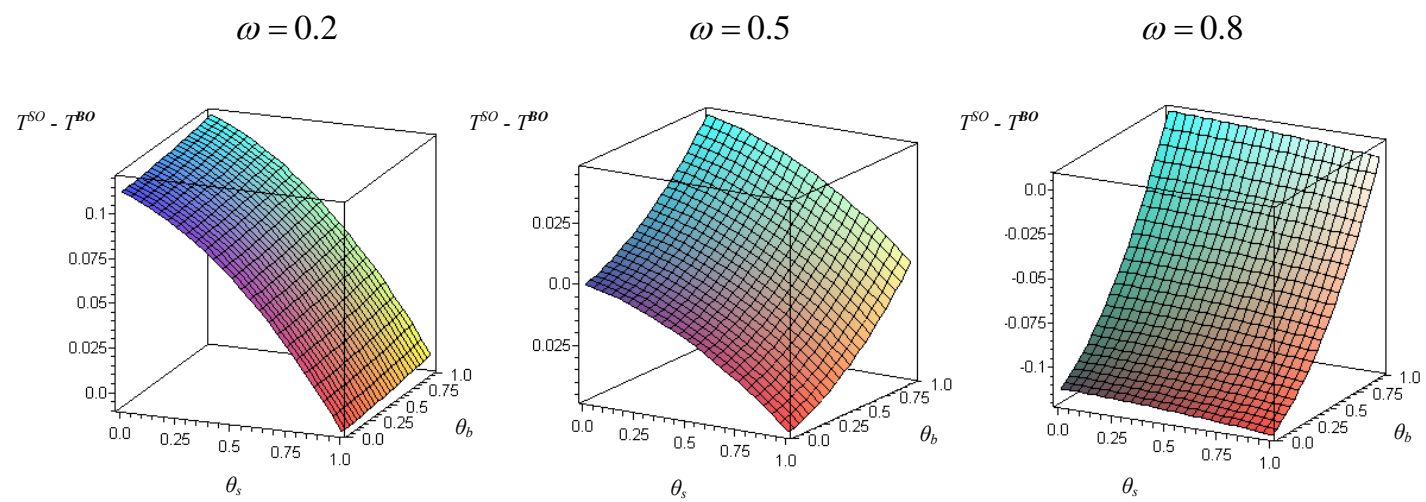

Figure 3: Total Surplus Difference between Supplier Ownership and Buyer Ownership $\left(T^{S O}{ }_{-}\right.$ $T^{B O}$ ) for Case 1 (Nash Bargaining; $\mu=0.5$ )

The above proposition reveals that the relationship between relative importance and optimal ownership structure is mediated by the specificity of the participants' investments. In particular, it implies that when the participants' specificity of investment is high, it is a more critical determinant of optimal ownership structure than the relative importance of investment.

As mentioned earlier, the supplier's investment is specific to the current relationship if the supplier does not have many trading partners or if every buyer has different system specifications and requirements with which the supplier needs to comply. Our model suggests

\footnotetext{
${ }^{8}$ This can be verified by taking partial derivatives of the difference in total surplus under the two ownership structures with respect to $\omega, \theta_{b}$, and $\theta_{s}$.
} 
that in such a case it is optimal for the buyer to own the VMI asset. In addition, the above results indicate that as technologies used in an IOS become more general (or more nonspecific) in the sense that they are easily redeployed and reused, the relative importance of participants' investments becomes more critical ? $^{9}$

Hart and Moore (1990) suggest that a participant's investment is always greater when it is the owner compared with when it is not. Our next proposition shows that it is possible for a participant's investment to increase even when it gives up the VMI asset ownership, if the positive investment externalities are strong enough.

\section{Proposition 3 (Positive Investment Externalities and Optimal Ownership)}

Let $\omega_{k}$ and $\theta_{k}, k \in\{i, j\}$, denote the relative importance and specificity of investment of the corresponding participant. Shifting ownership from participant $i$ to participant $j$ increases both participants' investment levels if the positive investment externalities are strong enough, as indicated by $\mu>\frac{2 \omega_{i}\left(1-\theta_{i}\right)}{\omega_{j}\left(1-\theta_{j}\right)}$.

Proof: See Appendix C.

For the inequality to hold, participant $j$ 's investment has to be substantially more important and/or less specific than participant $i$ 's. Thus, in the presence of strong positive externalities, not only the owner's but also the non-owner's investments may increase when the ownership is shifted to the participant with a more important investment. This may happen because the decrease in investment by the participant who does not own the asset is offset by the increase in investments due to the positive externalities. This suggests that in the presence of strong investment externalities, creating the right ownership structure becomes even more critical. In a supplier-buyer IOS relationship, this implies that the value impact of the ownership structure over IOS assets is greater as the supplier and the buyer integrate their systems and processes, making their investments more complementary. For example, when the supplier and the buyer have just established an EDI link and are exchanging simple electronic documents, the complementarities of their investments is low. As

\footnotetext{
${ }^{9}$ As mentioned earlier, specificity of investments can never be zero because IOS implementations always involve some degree of customization and integration with internal systems.
} 
they develop their EDI-based IOS relationship into VMI or CPFR, however, which involves a more substantial degree of systems and process integration and coordination, their investments become more complementary. Our modeling result suggests that the IOS participants should be careful in deciding the ownership structure of their IOS as they move from a simple EDI to VMI and CPFR.

One of Hart and Moore's key results is that it is optimal to give asset ownership to the participant with a relatively more important investment. de Meza and Lockwood (1998) and Chiu (1998) showed that Hart and Moore's result may not hold when we use the outside option principle as the bargaining solution. In our next proposition, we show that even when we use the outside option principle, optimal ownership is determined by the relationship between the participants' investment specificity and the relative importance of their investments.

\section{Proposition 4 (Outside Options, Relative Importance, and Specific Investment).}

Let $\omega_{k}$ and $\theta_{k}, k \in\{i, j\}$, denote the relative importance and specificity of investment of the corresponding participant. Under the outside option principle, if each participant's outside option binds when it is the owner, then ownership by participant $i$ is optimal if and only if $\omega_{i} \theta_{i}<\omega_{j} \theta_{j}$.

Proof: See Appendix C.

In other words, under the outside option principle, it is optimal to give the ownership of the VMI asset to the participant with a less important investment as long as its investment is not too specific relative to the other participant's investment. If the participant's investment is much more specific than the other participant, however, then it can be optimal for the other participant (whose investment is more important) to be the owner. For example, in the right panel of Figure 4, the buyer's investment is more important because $\omega>0.5$. The figure shows that buyer ownership will be optimal when the supplier's investment is much more specific (i.e., $\theta_{s} \gg \theta_{b}$ ). This occurs when the total surplus under the supplier's ownership, $T^{S O}$, is smaller than the total surplus under buyer ownership, $T^{B O}$, resulting in a negative difference, $T^{S O}-T^{B O}$. 

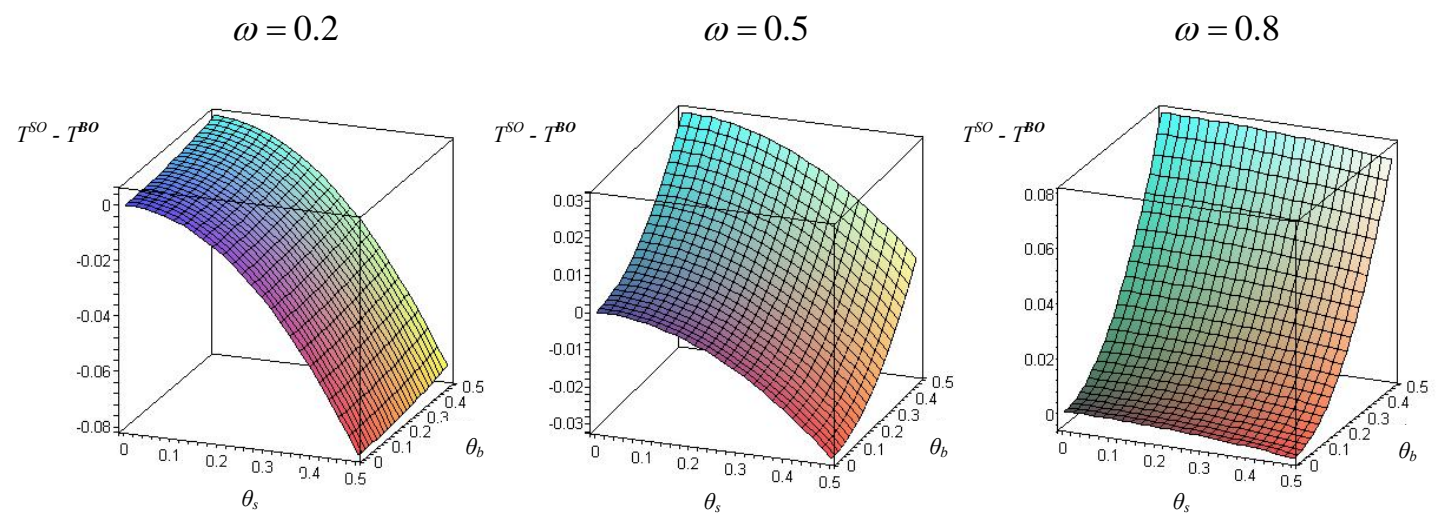

Figure 4: Total Surplus Difference between Supplier Ownership and Buyer Ownership $\left(T^{S O}{ }_{-}\right.$ $T^{B O}$ ) for Case 2 (Outside Option Principle)

To get some additional managerial insights, we next consider three possible situations that emphasize the dependence of the ownership structure outcome on the participants' relative importance and investment specificity. First, when a participant's investment is more important and more specific than the other participant's, the latter should be the owner. Second, when a participant's investment is more important but less specific than the other participants', it is still optimal for the latter to be the owner as long as its relative investment specificity is not too low. For example, if $\omega=0.8, \theta_{b}=0.2, \theta_{s}=0.4$, it is optimal for the supplier (whose investment is less important) to be the owner because $\omega \theta_{b}>(1-\omega) \theta_{s}$. Finally, when one participant's investment is more important but much less specific than the other's (so that the product of its $\omega$ and $\theta$ is smaller than that of the other participant), the former participant should be the owner. For example, if $\omega=0.8, \theta_{b}=0.05, \theta_{s}=0.4$, it is optimal for the buyer (whose investment is more important) to be the owner because $\omega \theta_{b}<(1-\omega) \theta_{s}$. This last result is the most notable because it shows that Hart and Moore's result holds even under the outside option principle.

Our last proposition can be explained from the perspective of equilibrium investments. From Table 2, we see that $x_{s}^{s *}=(1-\omega)\left(1-\theta_{s}\right)=(1-\omega)-(1-\omega) \theta_{s}$ and $x_{b}^{b *}=\omega\left(1-\theta_{b}\right)=$ $\omega-\omega \theta_{b}$. So, under either ownership structure, the owner's investment is reduced by the 
product of its relative importance and investment specificity, $(1-\omega) \theta_{s}$ and $\omega \theta_{b}$, as compared to when it does not own the VMI asset. This reduced investment in VMI implementation eventually diminishes the total value that is created from the system. Our proposition implies that it is optimal to give the VMI asset ownership to the participant whose investment is reduced less as the owner.

Then, how can we explain the different results that arise under the different bargaining mechanisms for dividing incremental value in VMI? As shown earlier, under the outside option principle, the value of the alternative opportunities outside the current relationship affects the bargaining outcome more than it does under Nash bargaining. As long as the specificity of the participants' investment is positive, the participants' investments increase the value from continuing bargaining $(V)$ more than the value of their outside options $\left(r_{b}\right.$ and $r_{s}$ ). This is equivalent to the outside option losing value with specific investments (Rajan and Zingales, 1998). By making specific investments and specializing assets to the relationship, a participant forgoes its alternative opportunities for reusing the assets outside the relationship. Eventually, losing alternative opportunities reduces the participant's incentives for specific investment. This negative impact of investment specificity (through outside options) is more severe when a participant's investment makes a greater impact on total value, that is, when the participant's investment is relatively more important. Therefore, it is optimal to give the ownership of the VMI asset to the participant with a less important investment under the outside option principle.

In our VMI example, this negative impact of specific investments is severe when the buyer and the supplier make irreversible or costly-to-undo investments in their VMI systems (e.g., systems integration and database schema changes). Our model suggests that participants should be careful when they make these investment decisions because they may lose opportunities for alternative uses of the VMI asset. This reduces their investment incentives and the total value from the asset. If the buyer and the supplier have to make those investments, then the participant whose investment makes the least contribution to the total value should be the owner. This minimizes the negative impact of irreversible investments. 


\section{Conclusion}

In today's network economy, firms increasingly are using IT to connect to suppliers and buyers, and to alliance partners and markets in their core operating regions and around the world. As a result, a variety of technologies that support interorganizational communications and transactions have become integral to their business infrastructures. Successful implementation of such systems requires substantial noncontractible investments by each participating firm in such areas as systems integration, data conversion, documentation and testing, and process redesign. In this study, drawing upon institutional economics and bargaining theory, we analyzed IOS ownership as a mechanism to coordinate the participants' joint investments in IOS implementation, thereby encouraging appropriate levels of necessary investments and maximizing the value the participants can appropriate. Although our discussions focused on IOS and vendor-managed inventory systems, the contributions of our research offer broader significance.

\subsection{Contributions}

First, building on the theoretical results of Bakos and Nault (1997), this work further informs IS researchers of the significance of IT asset ownership in IOS. This present research also builds on the modeling and case analysis of Han et al. (2004) on information exploitation and interorganizational system ownership. Although there have been many studies on IOS focusing on such issues as business value and adoption, little research has examined mechanisms by which firms can create and capture maximum value from their IOS. We believe this study can inform future research efforts in this direction. Second, we integrated the key concepts from two well-known institutional economic theories, the theory of incomplete contracts and transaction costs economics, within a single modeling framework. Although relative importance of investment and investment specificity have been separately studied and shown to impact the efficiency of ownership structures, we examined how these two factors are related in determining optimal ownership structures.

With VMI between a supplier and a buyer as an illustrative example of IOS, we presented 
an analytical model that incorporates participants' relative importance of investment and specificity of investment, the two key determinants of optimal ownership structures drawn from the theory of incomplete contracts and transaction cost economics. Using the Nash bargaining solution for 50:50 distribution of the jointly-produced surplus between participants, we first examined how different values of these two factors affect whether ownership structure, supplier ownership or buyer ownership of the VMI system is optimal, in the sense of maximizing the total surplus. We showed why relative importance of investment determines which ownership structure is optimal, when participants' investments are moderately specific. We also demonstrated that specificity of investment is a more critical determinant than relative importance of investment when the participants' investment specificity is very high. As technologies have become more general in their purposes, in the sense that they are ever more easily redeployed and reused, we expect relative importance of investment to become an emerging dominant factor.

We showed that in the presence of strong positive investment externalities from participating firms' IOS investments, shifting the ownership of IOS to a participant with a more important investment increases both participants' investments. This means that when the processes and systems between the buyer and the supplier are highly integrated, choosing the appropriate ownership structure in IOS is even more critical. We further analyzed our model using another bargaining mechanism, the outside option principle, in which the value of outside opportunities affects the bargaining outcome. We also showed that the participant whose investment incentive is reduced less by its investment specificity, when it is the owner, should be the owner of IOS. We learned that, compared with the case based on the Nash bargaining solution, specificity of investment plays a bigger role when the outside option principle is used as the bargaining mechanism. This is because when disagreement payoffs are interpreted as outside options and the owner's outside option binds, the owner's payoff is essentially the same as its outside option, and this is directly affected by the specificity of its investment. In contrast, under the 50:50 surplus split arrangements involved in Nash bargaining, a participant's threat point is a relatively small part of its payoff.

Which interpretation of disagreement payoffs - threat points or outside options - is more 
viable in the context of IOS, then? Taking an outside option implies permanently terminating bargaining (without the possibility of future cooperation) with the current partner, whereas adopting a threat point does not rule out the possibility of cooperation with the current partner in the future. Thus, the critical difference between threat points and outside options is whether the participant is allowed to cooperate with the current partner in the future. In the context of IOS, the question becomes: Would terminating the relationship with the current IOS partner and reusing the system assets to connect with other partners preclude the IOS owner from going back to the relationship with the former partner? Given that ITs used in IOS are increasingly open standards-based, and technology solutions for integrating different systems are widely available, we believe that, in general, the answer is "No." The IOS owner can reuse its system assets for cooperating with the former partner. This means that our results based on Nash bargaining (Case 1) are applicable to most situations involving IOS. There are some situations, however, in which contractual obligations preclude a participant from cooperating with its former partner (e.g., something similar to a non-compete clause in employment contracts). This is possible when the current partner and the former partner become competitors, and there are key intellectual property rights involved in the operation of the IOS.

On a practical front, we offer normative guidance on how senior managers should make value-maximizing decisions with respect to ownership of IT assets in interorganizational relationships. Managers may not be sensitive enough to IT asset ownership issues when making IOS investment and implementation decisions. Because of the uncertain payoffs, many participants may wish to own fewer IT assets to mitigate the risky costs associated with implementation failure, and let their business partners own more IT assets. Ironically, without the appropriate incentive that comes from IT asset ownership, many managers underinvest in implementation activities. This makes it more likely that their implementations will fail. Our modeling results suggest that they need to pay more attention to ownership issues related to IT assets in IOS. In particular, they need to evaluate their IOS in terms of the relative importance of investment and the specificity of investment before making an IOS ownership decision. 
A second aspect of the contribution of this research to practice comes in its alignment with the emerging discipline of services science, management and engineering (SSME) (Chesbrough and Spohrer, 2006; Maglio et al., 2005). Recent efforts made by IBM T. J. Watson Research Center and IBM Almaden Services Research, among other leading IT services firms, have prompted an increasing awareness in the business and university research community that understanding how to manage contracts for IT services, business partnerships and ownership structures for IT investments, and other strategic interorganizational relationships related to technology infrastructures will be critical for organizational success in the next stages of IT-supported business innovation. Services science broadly emphasizes the importance of modeling, analyzing and understanding fundamental relationships related to IT investments, management and control-related issues that permit value maximization. As such, we hope that readers of this article will recognize the importance of our research for its effort to solve an important set of managerial problems with respect to technology in the services science domain, as well as for the specific results that it offers regarding relative importance and specificity of investment in the structuring of ownership for interorganizational IT investments.

\subsection{Applications, Limitations and Future Research}

Following on our arguments for the academic contributions and managerial relevance of this research, we conclude by considering the applications and limitations of the modeling perspective that we have proposed for ownership structure related to interorganizational IT assets. We do this based on a number of characteristics of the settings and the managerial goals associated with ownership structure analysis. The key question is: Under what circumstances does it make sense to apply our approach to evaluating ownership structure?

First, the reader should recognize that there are a number of "classical" dimensions of the IT ownership problem that we have studied which go along with analysis under the theory of incomplete contracts. For example, it must be possible for a firm to actually own an IT asset in an interorganizational relationship - and not be prohibited from doing so by industry or government regulations. Another consideration is whether the firm may not 
wish to be an owner due to the possibility of litigation arising from perceptions about unfair competitive practices. We saw this with respect to electronic banking network support of interstate bank branching in the 1980s and 1990s, where preventative measures were put in place to disallow the largest banks in the United States (e.g., Citibank, Bank of America, BancOne (Ohio), etc.) from building shared IT infrastructure for consumer banking far beyond their core regions of operation. Very likely, due to their relative importance in a variety of proposed IT infrastructure co-investment relationships, the larger banks that sought entry into new operating territories would have been shown to be the appropriate owners of whatever infrastructure they built under the evaluation of our model. For example, we might think of such a large and high-tech nationwide commercial bank supplementing the efforts of then-First Bank System (now U.S. Bancorp) of Minnesota for increasing the sophistication of its electronic banking systems in the 1990s. Although our theory might have predicted that a banking firm like Citibank or Bank of America would be the logical owner of the network if it had become involved, it is worth observing that non-IT aspects of interorganizational relationships - in this case, pre-established customer relationships in the Upper Midwest - also would have played an important role in the mix with respect to the surplus created by co-investments in technology. As a result, even today we see banks such as U.S. Bancorp in that region of the U.S., where banking relationships with customers are long-standing, continuing to own and operate their own electronic banking networks,

Another relevant case involved the commercial bank, J. P. Morgan, whose early electronic corporate bond issuance market, Capitalink, was created in association with a one-time senior executive in corporate finance from Seagram's International. This case points to the need to take into account the way that time will be likely to affect the participants' perceptions of optimal ownership structure. Development of Capitalink was held up by the Securities Exchange Commission (SEC) from operating or being syndicated for joint ownership by Morgan with other investment banks, due to the shelf registration restrictions associated with SEC Rule 415 of the time. They prohibited commercial banks from exercising the operating powers of investment banks, especially related to the formation of capital through the issuance of stocks and bonds. Nevertheless, an analyst working on the basis of our theory in the early 1990s would surely have recognized the extent to which Morgan 
exhibited a first-mover's relative importance from technological innovation in the creation of surplus from joint investments for electronic debt issuance infrastructure. Morgan could have explored interorganizational technology investments for Capitalink with the investment banking industry leaders of its time, Merrill Lynch, Salomon Brothers, First Boston Corporation, or Goldman Sachs. This would have brought Morgan's technological innovations together with the installed base of institutional investment banking and corporate debt issuance clients. Unfortunately though, opportunities for value appropriation associated with electronic issuance innovations would diminish with the repeal of Glass-Steagall prohibitions against commercial banking firms conducting investment banking operations. This would have led to a temporal shift in the relative importance of the technological innovator, as its innovation was imitated, to firms that owned the investment banking relationships in which debt issuance services were offered. Even if it had been successful in forging interorganizational IT investment from an investment bank, the specificity of investment that characterized the early version of Capitalink would have made it a difficult asset for which Morgan could exercise outside options.

Second, the settings in which our ownership structure analysis approach will apply should present similar risks to the investing participants, and these risks, moveover, should be driven mostly by noncontractibility. The risks should not be dramatically different for either participant. Nor should the global risks of investment that are perceived swamp the perceived risks associated with the noncontractible aspects of the investments in the technologies that underlie the firms' collaboration. If this is the case, then how the returns to joint investments are split is not likely to be of paramount importance to either party; instead, loss avoidance and positioning for financial risk management will be more critical. We expect this will occur, even to the extent of making sure that the threat points associated with dissolving the IT investment contract in the midst of the investment project can be invoked. We have often seen this occur in technology investment alliances for joint development of proprietary technology and their related standards (Axelrod et al., 1995; Gupta et al., 2008). There is a competitive scenario that plays out beyond the bounds of the joint venture participation or ownership structures that are selected by the firms involved in them. Changes in the market that result in standards drift may be especially problematic (Kauffman and Li, 2005), for ex- 
ample, and create additional impetus for considering temporal changes in optimal ownership. Indeed, we expect this to influence all aspects of the investment relationship: the relative importance of a firm's investment, the specificity of the investment relative to the changing market, and the amount of the value flows that participants are able to appropriate. So if there are many changes that are expected in the technological and business environments of the interorganizational IT investment setting, our model may only be suitable for approximating optimality in ownership structure at a single point in time. Still, we believe that it will be useful as the starting point for assessing a value trajectory for ownership structure under such conditions of analysis, as opposed to the expected value of deciding upon optimal ownership structure once and for all.

Third, it makes sense to consider whether the emphasis is on relative contributions to surplus produced, or on relative contributions to surplus protected in the application of our model. We have emphasized value maximization through a primal formulation of the problem of optimizing IOS ownership structure. It is possible, however, that different participants will bring different degrees of payoff-stabilizing influences. These, in turn, may help to ensure that full value appropriation is possible in joint investments by both participants, when ownership structure is an issue. In parallel with the long-standing argument that contributions to surplus from co-investment are an important driver of ownership, we may also view relative importance in terms of relative contributions to risk mitigation in an IOS investment relationship. This suggests that there may be circumstances under which relative importance, as we have defined it, is a little too narrowly specified. The same reasoning applies to specificity of investment, which may be risk-mitigating in an IT investment relationship for other reasons. A setting that illustrates these ideas has recently been suggested by Gupta and Zhdanov (2007), who investigated the incentives that multiple firms have for joint investments to achieve a shared level of information security. They proposed the idea of a managed security service provider (MSSP). An MSSP can be either a separate third party which undertakes its own information security services-related investments, or the result of coalition-based investment and management for improved information security. The purpose is protection of surplus in either individual or joint operations, through a technological approach to risk management that diminishes the variance of payoff-related outcomes. When 
information security involves joint investments to increase the firms' degree of confidence in the outcomes and payoffs, this suggests a dual formulation of our model - one that emphasizes the minimization of costs or cost efficiency in the achievement of surplus within some bounds of statistical confidence (Kauffman and Sougstad, 2007).

A final requirement for the modeling framework that we have discussed to be valid is its in-isolation consideration of co-investment and ownership of individual IOS assets. The real-world, of course, presents a much richer picture of organizations that have multiple strategic alliances and different joint ventures involving IOS assets with other firms. A more realistic view is that IT co-investment opportunities may not always be separable for ownership analysis - even though specific projects may be initiated at specific points in time. Instead, they may involve business partners who have portfolios of different IOS investments, some of which may be with the same business partners, but others which may be "one-off" contractual arrangements with one-time partners. This points to the need to further modify our modeling approach, so that it is possible to consider how to optimize ownership structures for different IOS assets that have some interaction with one another.

Clearly, there are other aspects that further suggest additional avenues for follow-up future research and investigation, beyond our study of the IOS relationship between one buyer and one supplier. The incomplete contracting literature assumes, for example, that ex post renegotiation of contracts is costless and efficient. This does not seem to accurately describe some of the industry settings we have studied. This means that there would be no uncertainty other than the contractual incompleteness of the investments and payoffs. Thus, it would be interesting and fruitful to incorporate uncertainty (e.g., information asymmetry) in our model and examine how it may affect the outcomes. We also did not consider negative investment externalities. It did not make sense to do so in the context of VMI. In other IOS contexts though, some participants' investments may exhibit negative externalities, for example, due to competition, the implementation of alternative standards, or different underlying business practices. Future research might incorporate negative investment externalities alongside positive externalities for IOS assets-so-called countervailing externalities - as Kauffman and Kumar (2008) have recommended. Finally, although we 
use two different bargaining mechanisms, the Nash bargaining solution and the outside option principle, we have not provided any empirical evidence as to which mechanism better portrays managerial choices in real-world situations. A possible next step, then, is to empirically test predictions about optimal ownership structures that would arise from the two mechanisms, and see how they square with our theoretical predictions.

\section{References}

E. Anderson, The salesperson as outside agent or employee: a transaction cost analysis. Marketing Science 4(3) (1985) 234-254.

R. Axelrod, W. Mitchell, R. E. Thomas, D. S., Bennett and E. Bruderer, Coalition formation in standard-setting alliances, Management Science 41(9) (1995) 1493-1508.

J. Y. Bakos, Information links and electronic marketplaces: the role of interorganizational information systems in vertical markets. Journal of Management Information Systems 8(2) (1991) 31-52.

J. Y. Bakos and E. Brynjolfsson. From vendors to partners: information technology and incomplete contracts in buyer-supplier relationships. Journal of Organizational Computing 10(2) (1993) 301-328.

J. Y. Bakos and B. R. Nault, Ownership and investment in electronic networks. Information Systems Research 8(4) (1997) 321-341.

K. Binmore, A. Rubinstein and A. Wolinsky, The Nash bargaining solution in economic modeling. RAND Journal of Economics 17(2) (1986) 176-188.

K. Binmore, A. Shaked and J. Sutton, An outside option experiment. The Quarterly Journal of Economics 104(4) (1989) 753-770.

Booz Allen Hamilton and Giga Information Group, B2B exchanges: future hopes, current doubts. Cambridge, MA (November 2001).

E. Brynjolfsson, Information assets, technology, and organization. Management Science, 
40(12) (1994) 1645-1662.

C. Challener. Taking the VMI step to collaborative commerce. CMR Focus (November 20, 2000) 11-13.

H. Chesbrough and J. Spohrer, A research manifesto for services science, Communications of the ACM 49(7) (2006) 35-40.

S. Y. Chiu, Noncooperative bargaining, hostages, and optimal asset ownership. American Economic Review, 88(4) (1998) 882-901.

E. K. Clemons and P. R. Kleindorfer, An economic analysis of interorganizational information systems. Decision Support Systems 8(5) (1992) 431-446.

Q. Dai and R. J. Kauffman. Business models for Internet-based e-procurement systems: an exploratory assessment. International Journal of Electronic Commerce 6(4) (2002) 41-72.

D. de Meza and B. Lockwood, Does asset ownership always motivate managers? outside options and the property rights theory of the firm. The Quarterly Journal of Economics 113(2) (1998) 240-252.

J. Gebauer and P. Buxmann, Assessing the value of interorganizational systems to support business transactions. International Journal of Electronic Commerce 4(4) (2000) 61-82.

S. F. Grossman and O. Hart, The costs and benefits of ownership: a theory of vertical and lateral integration. Journal of Political Economy 94(4) 1986) 691-719.

F. Gul, Bargaining foundations of Shapley value. Econometrica 57(1) (1989) 81-95.

A. Gupta, R. J. Kauffman and A. P. Wu, Do firm R\&D investments drive decisions to join? On the value of standard-setting in the consumer electronics industry, In R. Sprague (ed.), Proceedings of the 41st Hawaii International Conference on Systems Science, Kona, HI, January 2008 (Los Alamitos, CA: IEEE Computer Society Press, 2008).

A. Gupta and D. Zhdanov, Growth and sustainability of managed security services networks: An economic perspective. Working paper, Carlson School of Management, University of Minnesota, Minneapolis, MN, 2007. 
K. Han, R. J. Kauffman and B. R. Nault, Information exploitation and internorganizational systems ownership. Journal of Management Information Systems 21(2) (2004) 109-135.

O. Hart and J. Moore, Property rights and the nature of the firm. Journal of Political Economy 98(6) (1990) 1119-1158.

P. Hart and C. Saunders, Power and trust: critical factors in the adoption and use of electronic data interchange. Organization Science 8(1) (1997) 23-42.

M. Jensen and W. Meckling, Knowledge, control and organizational structure: parts I and II, in L. Werin and H. Hijkander (eds.), Contract Economics, (Basil Blackwell: Cambridge, UK, 1992).

G. John and B. A. Weitz, Forward integration into distribution: an empirical test of transaction cost analysis. Journal of Law, Economics, and Organization, 4(2) (1988) 337-355.

H. R. Johnston and M. R. Vitale, Creating competitive advantage with interorganizational information systems. MIS Quarterly 12(2) (1988) 153-165.

R. J. Kauffman and A. Kumar, Countervailing and complementary network effects and embedded options: Decision-making under uncertainty for technology investments, Information Technology and Management, 2008, forthcoming.

R. J. Kauffman and X. Li, Technology competition and optimal investment timing: a real options perspective. IEEE Transactions on Engineering Management, 52(1) (2005) 15-29.

P. P. Maglio, S. Srinivasan, J. T. Kreulen and J. Spohrer, Service systems, service scientists, SSME, and innovation, Communications of the ACM 49(7) (2006) 81-85.

R. B. Myerson, Game Theory: Analysis of Conflict (Harvard University Press: Cambridge, MA, 1991).

J. Nash, Two-person cooperative games. Econometrica 21(1) (1953) 128-140.

E. J. Poon, K. J. Ashish, M. Christino, M. H. Honour, M. R. Fernandopulle, B. Middleton, J. Newhouse, L. Leape, D. W. Bates, D. Blumenthal, and R. Kaushal, Assessing the level of healthcare information technology adoption in the United States: a snapshot. BMC Med- 
ical Informatics Decision Making, 6(1) (2006) (available at www.biomedcentral.com/14726947/6/1, last accessed on September 18, 2007).

R. G. Rajan and L. Zingales, Power in a theory of the firm. The Quarterly Journal of Economics 113(2) (1998) 387-432.

F. J. Riggins, C. H. Kriebel, and T. Mukhopadhyay, The growth of interorganizational systems in the presence of network externalities. Management Science 40(8) (1994) 984-998.

A. Seidmann and A. Sundararajan, Building and sustaining interorganizational information sharing relationships: the competitive impact of interfacing supply chain operations with marketing strategy. In J. DeGross and K. Kumar (eds.), Proceedings of the 18th International Conference on Information Systems (Atlanta, GA, 1997) 205-222.

SPS Commerce, EDI outsourcing. Product description, St. Paul, MN (2007) (available at www.spscommerce.com/n_serv/buyer_edioutsourcing.shtml, last accessed on September 17, 2007).

Vendor Managed Inventory.com, VMI companies (2007) (available at www.vendormanagedinventory.com/company.htm, last accessed on September 18, 2007).

E. von Hippel, Sticky information and the locus of problem-solving: implications for innovation. Management Science 40(4) (1994) 429-439.

E. A. Walden, Intellectual property rights and cannibalization in information technology outsourcing contracts. MIS Quarterly 29(4) (2005) 699-720.

E. A. Walden and J. C. Wetherbe, Give a little, get a little. Harvard Business Review 83(9) (2005) 30-32.

M. Waller, M. E. Johnson, and T. Davis, Vendor-managed inventory in the retail supply chain. Journal of Business Logistics 20(1) (1999) 183-203.

E. T. G. Wang and A. Seidmann. Electronic data interchange: competitive externalities and strategic implementation policies. Management Science 41(3) (1995) 401-418.

O. E. Williamson, The Economic Institutions of Capitalism (Free Press: New York, NY, 
1985).

O. E. Williamson, The Mechanisms of Governance (Oxford University Press: Oxford, UK, 1996). 


\section{Appendices}

\section{A. Definition of Key Concepts}

\begin{tabular}{|c|c|c|}
\hline CONCEPT & DEFINITION & COMMENT \\
\hline $\begin{array}{l}\text { Relative } \\
\text { importance of } \\
\text { investment }\end{array}$ & $\begin{array}{l}\text { The relative magnitude of the contribution of } \\
\text { participants' incremental investments to the IOS } \\
\text { relationship. }\end{array}$ & $\begin{array}{l}\text { The most critical source of } \\
\text { relative importance is the } \\
\text { difference in the } \\
\text { participants' specific } \\
\text { knowledge about how to } \\
\text { create value. }\end{array}$ \\
\hline $\begin{array}{l}\text { Investment } \\
\text { specificity }\end{array}$ & $\begin{array}{l}\text { A loss in the value of a participant's investment } \\
\text { when the asset is used outside the current IOS } \\
\text { relationship. }\end{array}$ & $\begin{array}{l}\text { Participants' investment } \\
\text { specificity may differ } \\
\text { because of the differences in } \\
\text { their opportunities to reuse } \\
\text { the asset outside the current } \\
\text { relationship. }\end{array}$ \\
\hline $\begin{array}{l}\text { Disagreement } \\
\text { payoffs }\end{array}$ & $\begin{array}{l}\text { Payoffs that participants receive when they fail to } \\
\text { reach an agreement in bargaining. }\end{array}$ & $\begin{array}{l}\text { Disagreement payoffs can } \\
\text { be interpreted as either } \\
\text { threat points or outside } \\
\text { options. }\end{array}$ \\
\hline Threat points & $\begin{array}{l}\text { Payoffs that the participants engaged in bargaining } \\
\text { receive when the bargaining process continues with } \\
\text { no agreement reached (used in Case } 1 \text { ). }\end{array}$ & \multirow{2}{*}{$\begin{array}{l}\text { Taking the outside option } \\
\text { means giving up the original } \\
\text { opportunity for cooperation } \\
\text { with the bargaining partner, } \\
\text { while adopting a threat point } \\
\text { does not rule out the } \\
\text { possibility of cooperation in } \\
\text { the future. }\end{array}$} \\
\hline Outside options & $\begin{array}{l}\text { Payoffs that the participants receive when the } \\
\text { bargaining has been permanently terminated and } \\
\text { each participant uses outside opportunities without } \\
\text { the other participant's collaboration (used in Case 2). }\end{array}$ & \\
\hline
\end{tabular}




\section{B. Summary of Notation}

\begin{tabular}{|c|l|}
\hline NOTATION & \multicolumn{1}{|c|}{ DESCRIPTION } \\
\hline$b$ & Buyer \\
\hline$s$ & Supplier \\
\hline$x_{b}, x_{s}$ & Noncontractible investments by the buyer and the supplier, $x_{b}, x_{s} \in[0, x]$ \\
\hline$V\left(x_{b}, x_{s}\right)$ & Joint value created from the VMI system, $V(0,0)=0,\left.\frac{\partial V}{\partial x_{i}}\right|_{x_{i}=0}=\infty,\left.\frac{\partial V}{\partial x_{i}}\right|_{x_{i}=\bar{x}_{i}}=0, i \in\{s, b\}$. \\
\hline$c\left(x_{i}\right)$ & Investment cost, $c(0)=0, c^{\prime}(0)=0, c^{\prime \prime}(x)=\infty$ \\
\hline$a$ & $\begin{array}{l}\text { Indicator of ownership structure: } a=1 \text { indicates buyer ownership, and } a=0 \text { indicates supplier } \\
\text { ownership. }\end{array}$ \\
\hline$r_{i}\left(x_{i} \mid a\right)$ & $\begin{array}{l}\text { Disagreement payoffs (standalone value); When participant } i \text { is the non-owner, } r_{i}\left(x_{i} \mid a\right)=0 ; \\
\text { When participant } i \text { is the owner, } r_{i}(0 \mid a)=0, r_{i}^{\prime}(0 \mid a)=\infty, r_{i}^{\prime}\left(\overline{x_{i}} \mid a\right)=0\end{array}$ \\
\hline$\theta_{i}$ & Relative importance of the buyer's investment, $0 \leq \omega \leq 1$ \\
\hline$\mu$ & Participant $i$ 's investment specificity, $0 \leq \theta_{i} \leq 1$ \\
\hline$T\left(x_{b}, x_{s}\right)$ & Positive investment externalities between the buyer and the supplier, $0 \leq \mu \leq 1$ \\
\hline$T^{S O}, T^{B O}$ & Total surplus net of the costs \\
\hline$x_{b}^{*}, x_{s}^{*}$ & Total surplus net of the costs under supplier ownership and buyer ownership, respectively \\
\hline$x_{b}^{s 0}, x_{s}^{s o}$ & First-best equilibrium investments \\
\hline$x_{b}^{B O}, x_{s}^{B O}$ & Equilibrium investments under supplier ownership in Case 1 \\
\hline$\pi_{b}, \pi_{s}$ & Equilibrium investments under buyer ownership in Case 1 \\
\hline$s_{b}, s_{s}$ & Payoffs to the buyer and the supplier (net of the costs) \\
\hline$x_{i}{ }^{*}$ & Surplus for the buyer and the supplier in Case 2 \\
\hline & $\begin{array}{l}\text { Participant } i \text { 's equilibrium investment when } j \text { 's outside option binds, } i \in\{s, b\}, j \in\{s, b, n\}, \\
j=n \text { if neither outside option binds. }\end{array}$ \\
\hline
\end{tabular}




\section{Proofs of the Propositions}

Proof of Proposition 2. Let $T^{S O}$ and $T^{B O}$ denote the total surplus under supplier ownership and buyer ownership. Based on the equilibrium investment levels in Case 1 (see Table 2), we have:

$$
\begin{aligned}
T^{S O}\left(\omega, \theta_{s}\right)= & \frac{2 \omega^{2}+\mu \omega(1-\omega)\left(2-\theta_{s}\right)}{4-\mu^{2}}+\frac{2(1-\omega)^{2}\left(2-\theta_{s}\right)+\mu \omega(1-\omega)}{4-\mu^{2}} \\
& +\frac{\mu\left\{2 \omega+\mu(1-\omega)\left(2-\theta_{s}\right)\right\}\left\{2(1-\omega)\left(2-\theta_{s}\right)+\mu \omega\right\}}{\left(4-\mu^{2}\right)^{2}} \\
& -\frac{\left[\left\{2 \omega+\mu(1-\omega)\left(2-\theta_{s}\right)\right\}^{2}+\left\{2(1-\omega)\left(2-\theta_{s}\right)+\mu \omega\right\}^{2}\right]}{2\left(4-\mu^{2}\right)^{2}} \\
T^{B O}\left(\omega, \theta_{b}\right)= & \frac{2 \omega^{2}\left(2-\theta_{b}\right)+\mu \omega(1-\omega)}{4-\mu^{2}}+\frac{2(1-\omega)^{2}+\mu \omega(1-\omega)\left(2-\theta_{b}\right)}{4-\mu^{2}} \\
& +\frac{\mu\left\{2 \omega\left(2-\theta_{b}\right)+\mu(1-\omega)\right\}\left\{2(1-\omega)+\mu \omega\left(2-\theta_{b}\right)\right\}}{\left(4-\mu^{2}\right)^{2}} \\
& -\frac{\left[\left\{2 \omega\left(2-\theta_{b}\right)+\mu(1-\omega)\right\}^{2}+\left\{2(1-\omega)+\mu \omega\left(2-\theta_{b}\right)\right\}^{2}\right]}{2\left(4-\mu^{2}\right)^{2}}
\end{aligned}
$$

To determine which ownership structure is optimal, we compare these total surplus func- 
tions by calculating the difference. Factoring out $\frac{1}{2\left(4-\mu^{2}\right)^{2}}$, we get:

$$
\begin{aligned}
\frac{T^{S O}-T^{B O}}{2\left(4-\mu^{2}\right)^{2}=} & 2\left(4-\mu^{2}\right)\left\{2 \omega^{2}+\mu \omega(1-\omega)\left(2-\theta_{s}\right)+2(1-\omega)^{2}\left(2-\theta_{s}\right)\right. \\
& +\mu \omega(1-\omega)\}+2 \mu\left\{4 \omega(1-\omega)\left(2-\theta_{s}\right)+2 \mu \omega^{2}+2 \mu(1-\omega)^{2}\left(2-\theta_{s}\right)^{2}\right. \\
& \left.+\mu^{2} \omega(1-\omega)\left(2-\theta_{s}\right)\right\}-\left\{4 \omega^{2}+4 \mu \omega(1-\omega)\left(2-\theta_{s}\right)+\mu^{2}(1-\omega)^{2}\left(2-\theta_{s}\right)^{2}\right. \\
& \left.+4(1-\omega)^{2}\left(2-\theta_{s}\right)^{2}+4 \mu \omega(1-\omega)\left(2-\theta_{s}\right)+\mu^{2} \omega^{2}\right\} \\
& -2\left(4-\mu^{2}\right)\left\{2 \omega^{2}\left(2-\theta_{b}\right)+\mu \omega(1-\omega)+2(1-\omega)^{2}\right. \\
& \left.+\mu \omega(1-\omega)\left(2-\theta_{b}\right)\right\}-2 \mu\left\{4 \omega(1-\omega)\left(2-\theta_{b}\right)+2 \mu \omega^{2}\left(2-\theta_{b}\right)^{2}+2 \mu(1-\omega)^{2}\right. \\
& \left.+\mu^{2} \omega(1-\omega)\left(2-\theta_{b}\right)\right\}+\left\{4 \omega^{2}\left(2-\theta_{b}\right)^{2}+4 \mu \omega(1-\omega)\left(2-\theta_{b}\right)+\mu^{2}(1-\omega)^{2}\right. \\
& \left.+4(1-\omega)^{2}+4 \mu \omega(1-\omega)\left(2-\theta_{b}\right)+\mu^{2} \omega^{2}\left(2-\theta_{b}\right)^{2}\right\} \\
= & 16 \omega^{2}+8 \mu \omega(1-\omega)\left(2-\theta_{s}\right)+16(1-\omega)^{2}\left(2-\theta_{s}\right)-4 \mu^{2}(1-\omega)^{2}\left(2-\theta_{s}\right) \\
& +4 \mu^{2}(1-\omega)^{2}\left(2-\theta_{s}\right)^{2}-4 \omega^{2}-\mu^{2}(1-\omega)^{2}\left(2-\theta_{s}\right)^{2}-4(1-\omega)^{2}\left(2-\theta_{s}\right)^{2}-\mu^{2} \omega^{2} \\
& -16 \omega^{2}\left(2-\theta_{b}\right)-16(1-\omega)^{2}-8 \mu \omega(1-\omega)\left(2-\theta_{b}\right)+4 \mu^{2} \omega^{2}\left(2-\theta_{b}\right) \\
& -4 \mu^{2} \omega^{2}\left(2-\theta_{b}\right)^{2}+4 \omega^{2}\left(2-\theta_{b}\right)^{2}+\mu^{2}(1-\omega)^{2}+4(1-\omega)^{2}+\mu^{2} \omega^{2}\left(2-\theta_{b}\right)^{2} \\
= & -4 \omega^{2}\left(1-\theta_{b}\right)\left(1+\theta_{b}\right)+4(1-\omega)^{2}\left(1-\theta_{s}\right)\left(1+\theta_{s}\right) \\
& +\mu^{2}(1-\omega)^{2}\left(1-\theta_{s}\right)\left(5-3 \theta_{s}\right)-\mu^{2} \omega^{2}\left(1-\theta_{b}\right)\left(5-3 \theta_{b}\right) \\
= & \left(1-\omega^{2}\right)\left(1-\theta_{s}\right)\left\{4\left(1+\theta_{s}\right)+\mu^{2}\left(5-3 \theta_{s}\right)\right\}-\omega^{2}\left(1-\theta_{b}\right)\left\{4\left(1+\theta_{b}\right)+\mu^{2}\left(5-3 \theta_{b}\right)\right\} \\
& +\mu{ }^{2}(1-\omega)
\end{aligned}
$$

This expression should be positive for the supplier ownership to be optimal. More generally, if we let $\omega_{k}, k \in\{i, j\}$ and $\theta_{k}, k \in\{i, j\}$ denote the relative importance and specificity of investment of the corresponding participant, giving the ownership to participant $i$ is optimal if:

$$
\omega_{i}^{2}\left(1-\theta_{i}\right)\left\{4\left(1+\theta_{i}\right)+\mu^{2}\left(5-3 \theta_{i}\right)\right\}>\omega_{j}^{2}\left(1-\theta_{j}\right)\left\{4\left(1+\theta_{j}\right)+\mu^{2}\left(5-3 \theta_{j}\right)\right\}
$$

Proof of Proposition 3. Because the two ownership structures are mirror images, we just consider a case where the ownership of the VMI asset is shifted from the supplier to the buyer. We calculate the change in each participant's investment level as follows: 


$$
\begin{aligned}
x_{b}^{B O}-x_{b}^{S O} & =\frac{1}{4-\mu^{2}}\left\{4 \omega-2 \omega \theta_{b}+\mu(1-\omega)-2 \omega-2 \mu(1-\omega)+\mu(1-\mu) \theta_{s}\right\} \\
& =\frac{1}{4-\mu^{2}}\left\{2 \omega\left(1-\theta_{b}\right)-\mu(1-\omega)\left(1-\theta_{s}\right)\right\}, \\
x_{s}^{B O}-x_{s}^{S O} & =\frac{1}{4-\mu^{2}}\left\{2(1-\omega)+2 \mu \omega-\mu \omega \theta_{b}-4(1-\omega)+2(1-\omega) \theta_{s}-\mu \omega\right\} \\
& =\frac{1}{4-\mu^{2}}\left\{\mu \omega\left(1-\theta_{b}\right)-2(1-\omega)\left(1-\theta_{s}\right)\right\} .
\end{aligned}
$$

For these two expressions to be positive, the following two inequalities must hold: $\frac{2 \omega}{\mu(1-\omega)}>$ $\frac{\left(1-\theta_{s}\right)}{\left(1-\theta_{b}\right)}$ and $\frac{\mu \omega}{2(1-\omega)}>\frac{\left(1-\theta_{s}\right)}{\left(1-\theta_{b}\right)}$. Because $\frac{2 \omega}{\mu(1-\omega)}-\frac{\mu \omega}{2(1-\omega)}=\frac{\omega\left(4-\mu^{2}\right)}{2 \mu(1-\omega)}>0$, it suffices to have the latter inequality hold: $\frac{\mu \omega}{2(1-\omega)}>\frac{\left(1-\theta_{s}\right)}{\left(1-\theta_{b}\right)}$, which is equivalent to $\mu>\frac{2(1-\omega)\left(1-\theta_{s}\right)}{\omega\left(1-\theta_{b}\right)}$.

Let $\omega_{k}, k \in\{i, j\}$ and $\theta_{k}, k \in\{i, j\}$ denote the relative importance and specificity of investment of the corresponding participant. When the ownership is shifted from participant $i$ to participant $j$, the above inequality can be expressed in a more general form:

$$
\mu>\frac{2 \omega_{i}\left(1-\theta_{i}\right)}{\omega_{j}\left(1-\theta_{j}\right)} .
$$

Because $\mu \leq 1$, this inequality is more likely to hold when $\omega_{i}<\omega_{j}$ and $\theta_{i}>\theta_{j}$, that is, when participant $j$ 's investment is more important and less specific than participant $i$ 's.

Proof of Proposition 4. Let $T^{S O}$ and $T^{B O}$ denote the total surplus under the supplier ownership and the buyer ownership. Based on the equilibrium investment levels in Case 2 (see Table 2), we have:

$$
\begin{aligned}
& T^{S O}\left(\omega, \theta_{s}\right)=\omega^{2}+(1-\omega)^{2}\left(1-\theta_{s}\right)-\frac{1}{2}\left\{\omega^{2}+(1-\omega)^{2}\left(1-\theta_{s}\right)^{2}\right\} \\
& T^{B O}\left(\omega, \theta_{b}\right)=\omega^{2}\left(1-\theta_{b}\right)+(1-\omega)^{2}-\frac{1}{2}\left\{\omega^{2}\left(1-\theta_{b}\right)^{2}+(1-\omega)^{2}\right\} .
\end{aligned}
$$

To determine which ownership structure is optimal, we compare these total surplus functions by calculating the difference. Factoring out $1 / 2$, we get: 


$$
\begin{aligned}
\frac{T^{S O}-T^{B O}}{2}= & \omega^{2}+2(1-\omega)^{2}-2(1-\omega)^{2} \theta_{s}-(1-\omega)^{2}+2(1-\omega)^{2} \theta_{s}-(1-\omega)^{2} \theta_{s}^{2} \\
& -(1-\omega)^{2}-2 \omega^{2}+2 \omega^{2} \theta_{b}+\omega^{2}-2 \omega^{2} \theta_{b}+\omega^{2} \theta_{b}^{2} \\
= & \omega^{2} \theta_{b}^{2}-(1-\omega)^{2} \theta_{s}^{2} \\
= & \left\{\omega \theta_{b}+(1-\omega) \theta_{s}\right\}\left\{\omega \theta_{b}-(1-\omega) \theta_{s}\right\}
\end{aligned}
$$

For this expression to be positive (i.e., for the supplier ownership to be optimal), the following inequality must hold (because $\omega \theta_{b}+(1-\omega) \theta_{s}>0$ ):

$$
\omega \theta_{b}>(1-\omega) \theta_{s} .
$$

More generally, if we let $\omega_{k}, k \in\{i, j\}$ and $\theta_{k}, k \in\{i, j\}$ denote the relative importance and specificity of investment of the corresponding participant, giving the ownership to participant $i$ is optimal if

$$
\omega_{i} \theta_{i}<\omega_{j} \theta_{j} .
$$

